\title{
Princípios arquivísticos na literatura internacional e nacional: mapeamento do princípio da proveniência
}

\author{
Camila Lima Souza \\ camiladaniela.lima@gmail.com
}

Universidade de Brasília (UnB)

\begin{abstract}
Resumo: O Princípio da Proveniência, também conhecido como Princípio de Respeito aos Fundos e reconhecido como princípio fundamental da Arquivologia, e seus conceitos correlatos vêm sendo discutidos há mais de um século em vários países. Considerando a relevância desse princípio para a área, foi realizada uma seleção de obras da literatura internacional (29) e nacional (6), a partir de uma tese de doutorado que considerou o Manual dos Arquivistas Holandeses como marco teórico. A leitura e análise de 35 obras objetivou estudar o Princípio da Proveniência sob os seguintes aspectos: histórico e origens; definições; importância para a Arquivologia e, mais especificamente, para os demais princípios da área. A análise das obras permitiu visualizar as diversas abordagens teóricas e aplicações do princípio em questão em vários países, inclusive no Brasil, assim como as suas contribuições na consolidação da Arquivologia como disciplina científica.
\end{abstract}

Palavras-chave: arquivologia; princípio de respeito aos fundos; organicidade.

\begin{abstract}
The Principle of Provenance, known as The Principle of Respect des fonds and understood as the Archival Science core principle, and its related definitions have been discussed for centuries now all over several countries. Highlighting the principle meaning, we selected 29 international manuals and 6 Brazilian ones from a doctorate thesis which has considered the Dutch Manual as the theoretical framework. By reading and analyzing the 35 manuals, we aimed to study the Principle of Provenance under the following aspects: history and origin, definitions, importance to the Archival Science and particularly to the other principles. We could comprehend the different theorical and practical approaches in many countries including Brazil. In addition, we could recognize the principle contribution to consolidate the Archival Science as a scientific field.
\end{abstract}

Keywords: Archival Science; Principle of Provenance; Principle of Respect des fonds; Organicity. 


\section{INTRODUÇÃO}

Vários estudos da Arquivologia apresentam a importância dos princípios arquivísticos como delineadores da teoria arquivística e mediadores da comunicação do pensamento internacional da área, como aponta Marques (2011). Nesse sentido, o Princípio de Respeito aos Fundos, depois conhecido como Princípio da Proveniência ${ }^{1}$, tornar-se-ia a base teórica da Arquivologia, articulando os demais princípios em torno da informação orgânica registrada, objeto de estudo dessa disciplina.

O Princípio da Proveniência relaciona-se com a obrigatoriedade de não mesclar conjuntos documentais arquivísticos (fundos) de origens diferentes, prevendo uma articulação do organismo produtor do documento com a função que este representa. Nesse sentido, a sua aplicação também colabora no entendimento do contexto funcional relacionado à gênese documental.

Embora não exista consenso entre os estudiosos da área acerca da definição desses princípios, inicialmente tomamos como referência para a pesquisa o Dicionário de Terminologia Arquivística (ARQUIVO NACIONAL, 2005). Essa opção justificou-se pelo fato de esse Dicionário ter sido concebido pelo Arquivo Nacional, a principal instituição arquivística brasileira, e por ser a obra mais atual de terminologia arquivística do País, a qual contempla o Princípio da Proveniência, o Princípio do Respeito à Ordem Original ${ }^{2}$, o Princípio da Territorialidade $^{3}$, o Princípio da Reversibilidade ${ }^{4}$ e o Princípio da Pertinência ${ }^{5}$. Além desses princípios, o projeto de pesquisa maior, no qual este plano de trabalho inseriu-se, ${ }^{6}$ contempla

\footnotetext{
1 "Princípio básico da arquivologia segundo o qual o arquivo produzido por uma entidade coletiva, pessoa ou família não deve ser misturado aos de outras entidades produtoras. Também chamado princípio do respeito aos fundos" (ARQUIVO NACIONAL, 2005, p. 136).

2 "Princípio segundo o qual o arquivo deveria conservar o arranjo dado pela entidade coletiva, pessoa ou família que o produziu" (ARQUIVO NACIONAL, 2005, p. 137).

3 A proveniência territorial diz respeito ao "Conceito derivado do princípio da proveniência e segundo o qual arquivos deveriam ser conservados em serviços de arquivo do território no qual foram produzidos, excetuados os documentos elaborados pelas representações diplomáticas ou resultantes de operações militares" (ARQUIVO NACIONAL, 2005, p. 141).

4 "Princípio segundo o qual todo procedimento ou tratamento empreendido em arquivos pode ser revertido, se necessário" (ARQUIVO NACIONAL, 2005, p. 136).

5 "Princípio segundo o qual os documentos deveriam ser reclassificados por assunto sem ter em conta a proveniência e a classificação original. Também chamado princípio temático" (ARQUIVO NACIONAL, 2005, p. 141). Segundo os autores canadenses, esse princípio diz respeito à pertinência territorial, que é o "Princípio oposto ao princípio da proveniência e segundo o qual, sem terem em conta o local de criação, os arquivos deveriam ser entregues ao serviço dos arquivos com jurisdição arquivística sobre o território ao qual se reporta o seu conteúdo" (ROUSSEAU; COUTURE, 1998, p. 293).

${ }^{6}$ Este projeto foi desenvolvido no âmbito do Programa de Iniciação Científica (PROIC) da Universidade de Brasília (UnB), entre junho de 2011 e agosto de 2012, sob orientação da Prof.a Dra. Angelica Alves da Cunha Marques, do Curso de Arquivologia. Um projeto de pesquisa maior contemplou sete alunos do mesmo curso, com o objetivo de estudar os "Princípios arquivísticos na literatura internacional e nacional", a partir da tese de doutorado produzida pela professora (MARQUES, 2011).
} 
a Teoria das Três Idades ${ }^{7}$, de uso corrente no Brasil e no exterior, e o Princípio da Universalidade ${ }^{8}$, que também é referenciado na literatura (ROUSSEAU; COUTURE, 1998).

Diante das diferentes abordagens acerca da concepção, definição e repercussão desses princípios pelos autores da Arquivologia, concebemos um projeto de pesquisa que buscou investigar essas abordagens, por meio do mapeamento do Princípio da Proveniência na literatura arquivística internacional e nacional.

Desenvolvemos uma pesquisa descritiva e qualitativa, a qual contemplou a análise de 35 obras arquivísticas internacionais e nacionais, selecionadas a partir daquelas indicadas na literatura da área (MARQUES, 2011), apresentadas nas referências bibliográficas. Na seleção dessas obras, consideramos aquelas que seriam possíveis de serem localizadas e que satisfariam a nossa metodologia, excluindo as coletâneas e os artigos de periódicos.

A análise dessas obras considerou os seguintes aspectos: o que o(s) autor(es) apresentava(m) sobre o histórico e a origem do Princípio de Proveniência; se o(s) autor(es) apresentavam $(m)$ definição própria ou indireta do princípio; o que se poderia inferir das considerações do(s) autor(es) quanto à importância do princípio para a Arquivologia e, mais especificamente, para os demais princípios da área. A referida análise desenvolveu-se a partir de reuniões mensais com os membros do projeto de pesquisa, nas quais foram discutidos esses aspectos em relação aos demais princípios arquivísticos, por sua vez sintetizados num quadro, que permitiu a articulação dos resultados.

\section{MARCOS HISTÓRICOS}

Nas obras analisadas, as origens do Princípio da Proveniência foram abordadas, pelos autores, de formas diferentes. Muitos destacam somente uma data; outros fazem um apanhado histórico, sem definir a(s) origem(ns), apontando marcos históricos do princípio em diferentes países, a partir de vários estudos da Arquivologia. Outros autores, ainda, não consideram nenhuma origem, já que defendem que o princípio vem se desenvolvendo ao longo do tempo, de forma difusa. Segundo esses últimos autores, não se deve considerar um

\footnotetext{
7 "A abordagem das três idades assenta nas etapas de vida dos documentos. Na idade activa, o documento serve regularmente para a administração; na idade semiactiva, é utilizado ocasionalmente, e na idade inactiva, é destruído ou conservado de modo permanente" (ROUSSEAU; COUTURE, 1998, p. 53). No Brasil, as três idades são conhecidas, respectivamente, como: corrente, intermediária e permanente.

8 "Princípio que exige que o arquivista apreenda, compreenda, estruture, classifique, arrume e descreva a informação orgânica e registrada de forma global antes de passar a uma outra etapa mais pormenorizada. Este princípio atinge a sua justa medida naquilo a que se convencionou chamar a abordagem do geral para o particular, onde as unidades de trabalho se integram umas nas outras como mesinhas de encaixar ou bonecas russas" (ROUSSEAU; COUTURE, 1998, p. 296).
} 
marco e, sim, o desenvolvimento teórico do Princípio da Proveniência, o qual ainda estaria em processo de evolução conceitual.

Grande parte das obras analisadas afirma que a origem do Princípio fundamental da Arquivologia está na França do século XIX, mais especificamente em 24 de abril de 1841, quando o historiador Natalis de Wailly, chefe da seção administrativa dos arquivos departamentais do Ministério do Interior, emitiu uma circular na qual definia que os arquivos de um mesmo fundo deveriam ficar agrupados (CASANOVA, 1928; JENKINSON, 1965; BRENNEKE, 1968; DIRECTION DES ARCHIVES DE FRANCE, 1970; BERNER, 1983; CARUCCI, 1989; EASTWOOD, 1992; ROUSSEAU; COUTURE, 1998; SCHELLENBERG, 2006; CRUZ MUNDET, 2008; RUIZ RODRÍGUEZ, 2008).

Schellenberg (2010) explica essa parte da história arquivística lembrando que, durante a Revolução Francesa, dois bibliotecários se tornaram diretores dos Archives Nacionales da França, estabelecendo métodos de arranjo documental de acordo com esquemas de classificação predeterminados. Como muitos estudiosos da área entendem atualmente, essa é uma forma inadequada de classificação, uma vez que compromete o vínculo orgânico do documento com o seu produtor, bem como com o contexto funcional da sua criação. $\mathrm{O}$ autor explica, ainda, que a circular de 1841 foi fruto de ordens expedidas por Guizot (em 1839), ministro da Instrução Pública e chefe de gabinete, para que se agrupassem os documentos de acordo com a natureza das instituições que os criaram, ou seja, dando prioridade ao respect des fonds.

No Manual de Arranjo e Descrição, conhecido como "Manual dos Arquivistas Holandeses", e reconhecido como o primeiro manual arquivístico (CRUZ MUNDET, 2008; MARTíN-POZUELO CAMPILLOS, 1999; MARQUES, 2011), os autores relatam que "É oportuno, pois, indicar claramente que não se quer dizer que os arquivos reunidos no repositório-geral devam ser fundidos num único arquivo. Ao contrário, há que manter separado cada um deles" (MULLER; FEITH; FRUIN; 1973, p. 22). Em seguida, eles definem o "Respect des fonds" como a expressão que tem destaque na teoria arquivística, a qual "significa a manutenção da integridade do arquivo" (IDEM, p. 29) e que posteriormente tornar-se-ia o Princípio da Proveniência.

Ainda a respeito do histórico da formulação desse princípio, Schellenberg (1980, p.108) destaca que ele procede do princípio francês respect pour les fonds do período de 1839-1841 e que ele "determina apenas que se devem agrupar os papéis de acordo com a natureza da instituição que os acumulou". Porém, segundo esse autor, da forma como foi formulado, o princípio não se revela preciso na sua conceituação e nem é coerente na sua aplicação. Rousseau e Couture (1998, p.81), após questionamentos a respeito do alcance da Circular de 
1841, afirmam que Natalis de Wailly "tinha inicialmente e antes de mais nada objectivos de pura gestão administrativa". De uma maneira sutil, os autores apontam questionamentos a respeito da circular.

Em outra perspectiva, vários autores (SCHELLENBERG, 1973; HEREDIA HERRERA, 1991; CRUZ MUNDET, 1994; LODOLINI, 1993; MARTÍN-POZUELO CAMPILLOS, 1996; ROUSSEAU; COUTURE, 1994) registraram a importância desse marco histórico para a Arquivologia. Para eles, tanto o contexto como o próprio marco histórico caracterizam a diferença de um método antigo de classificação por assunto (ou segundo o princípio da pertinência, de acordo com vários autores) para um novo e padronizado método que revolucionou a história arquivística. Nesse sentido, Rousseau e Couture consideram que:

\begin{abstract}
Assim nasceu a primeira componente do princípio da proveniência segundo o qual cada um dos fundos de arquivos é diferente dos seus semelhantes. Ao propor esta abordagem (reunião dos documentos consoante a pessoa física ou moral que os criou ou recebeu), Natalis de Wailly acabava de fazer sair a arquivística da anarquia e, mais importante, instalava-a sobre uma base sólida que Ihe permitiria, posteriormente, evoluir normalmente para 0 estatuto de disciplina. (ROUSSEAU; COUTURE; 1994, p. 80).
\end{abstract}

Heredia Herrera (1986), na mesma linha de pensamento, demonstra a importância da origem do princípio para a área, ao relatar que esse simples princípio configura uma especial orientação da Arquivologia como disciplina, cuja qualidade essencial é a ordem no mais amplo sentido do termo. Dessa forma, a autora apresenta a organicidade documental, característica primordial do documento de arquivo, ao associá-lo com o seu produtor, dentro de um processo com estrutura determinada.

Por outro lado, Elio Lodolini (1993) ressalta que, apesar da sua importância, esse marco histórico ainda estava bastante longe da reconstituição da ordem original, já introduzida em arquivos espanhóis, dinamarqueses, italianos, alemães e holandeses.

Schellenberg (2006, p.245) explica que o Princípio do Respeito aos Fundos foi amplamente aplicado na Prússia, onde foi decidido que os documentos primeiramente deveriam ser agrupados "de acordo com as unidades administrativas que os criaram" e não como era feito na França, de acordo com a natureza das instituições. Esse autor, assim como Rousseau e Couture (1994), afirma que o Respect des fonds (da França) evoluiu para o Provenienzprinzip (Prússia), que, associado ao Registraturprinzip (Prússia), conseguiu atender às pesquisas, mantendo a relação que o documento poderia ter com a instituição produtora, por meio da função nele representada. 
Até o momento, esse tem sido o marco de maior consideração para os autores da área. Até mesmo dentre aqueles que consideram outras origens ou a evolução do princípio, há autores que declaram uma atenção maior e especial ao contexto que originou a circular de 1841, o que pode ser justificável pelos personagens envolvidos e suas atribuições profissionais, já que o próprio Natalys de Wailly era historiador e arquivista do Ministério do Interior da França.

Todavia, foram analisadas obras que, embora minoritariamente, defendem outras origens do Princípio da Proveniência. A obra de Lodolini (1993), Archivística, princípios y problemas, foi a que teve mais relatos acerca de origens do princípio, inclusive a mais antiga delas, referenciada na obra de Robert-Henri Bautier: o princípio teria surgido na França, em 1328, quando o rei pronunciou a ordem de manter a proveniência dos documentos. Mais adiante, Lodolini destaca que, em 1332, no Arquivo Geral de Cagliari, por meio de uma carta real, Afonso IV de Aragão relatou o que, de acordo com sua consideração, mais tarde foi declarado como "respeto de los fondos". O autor também faz menção à Vicenta Cortés Alonso, que considera outro marco no histórico do Princípio da Proveniência, em 1588, no Arquivo de Simancas, baseado numa instrução de Felipe II.

Na linha histórica, a próxima data indicada como origem do Princípio da Proveniência, dentre as obras analisadas, foi verificada na obra de Casanova (1928): 1790, no Arquivo das Índias (Sevilla), por meio de uma ordem real de conservar os documentos, de uma mesma origem, unidos entre si e separados de outra proveniência. Lodolini relata que, em 1791, este princípio também foi aplicado na Dinamarca e, a partir de 1816, nos arquivos alemães (PAPRITZ apud LODOLINI, 1990), mas que, somente no fim do século XIX, ter-se-ia expandido a todos os arquivos do Estado da Prússia. O mesmo autor também destaca que em 1826 o Princípio da Proveniência foi prescrito na Holanda, enquanto que o "respeto de los fondos" surgiu em 1839, em Roma, e em 1841, na França.

Cruz Mundet (2008), um dos defensores da origem do Princípio da Proveniência com a circular de 1841, apresenta razões para que as outras origens do Princípio da Proveniência não sejam consideradas. Para esse estudioso, elas significam um retrocesso para a disciplina arquivística, pois foram aplicações diversas, no tempo e no espaço e em fundos determinados, tendo uma existência muito limitada, já que não foram mantidas ao longo do tempo. Além disso, relata o autor que, em nenhum momento, foram precedidas de um processo de teorização ou seguidas de debates da comunidade arquivística que pudessem culminar na base teórica e científica para o princípio.

Houve autores que apresentaram, historicamente, o princípio, de forma múltipla, analisando-o sob a ótica de vários autores e origens, em diversos países, como é o caso de 
Heredia Herrera (1991), que indica a sua origem na França, Dinamarca, Prússia, Holanda e, por último, na Itália.

Martín-Pozuelo Campillos (1999, p. 25-27) defende que a formulação do Princípio da Proveniência não é fruto de um momento histórico, mas, sim, de uma evolução que acrescenta novidades a esse princípio. Dessa forma, a autora explica sobre as origens do princípio, retomando, inclusive, concepções de outros estudiosos. Ela contempla a análise histórica de três formas: 1) conforme as primeiras manifestações de sua prática; 2) de acordo com as suas primeiras aplicações para as posteriores formulações teóricas; 3) e, por fim, a própria formulação do Princípio da Proveniência, que vem se desenvolvendo com o tempo, em âmbito geográfico cada vez maior. Embora a autora não defina um único grande marco do princípio, ela considera que a primeira aproximação do enunciado teórico do Princípio da Proveniência foi em 6 de abril de 1819, em uma aula histórico-filológica da Academia de Ciência de Berlim, na qual foi anunciado algo que não teve caráter de princípio mas, de uma orientação que mais tarde foi relacionado à ordem interna dos documentos.

Diante das diversas abordagens apresentadas, verificamos, portanto, que não há consenso quanto às origens temporais e geográficas do Princípio da Proveniência, tampouco, quanto aos seus marcos históricos.

\section{DEFINIÇÕES}

Observamos que vários autores apresentam definições, diretas ou indiretas, para o conceito de Princípio da Proveniência (MULLER; FEITH; FRUIN, 1973; CASANOVA, 1928; BRENNEKE, 1968; JENKINSON, 1965; SCHELLENBERG, 2006; TANODI, 1961; HEREDIA HERRERA, 1991; DIRECTION DES ARCHIVES DE FRANCE, 1970; CRUZ MUNDET, 2008; LODOLINI, 1928; FAVIER, 1985; ROUSSEAU; COUTURE, 1994; MARTÍN-POZUELO CAMPILLOS, 1999; BERNER, 1983; CARUCCI, 1989; GALLEGO DOMINGUEZ; LOPEZ GOMEZ, 1989; EASTWOOD, 1992).

Dentre esses autores, foi possível analisar aqueles que definem o Princípio da Proveniência como princípio independente. Os arquivistas holandeses, Muller, Feith e Fruin (1973, p.29), o apresentam como a "manutenção da integridade do arquivo". Schellenberg (1980, p. 121) o define, distinguindo-o do Princípio de Respeito à Ordem Original. O autor relata que, enquanto o Princípio da Proveniência "se revela fundamental e inflexível" o da "Ordem Original diz respeito, primacialmente, aos aspectos de conveniência e uso".

Casanova (1928), por sua vez, observa que o princípio que é reconhecido teoricamente exige que cada conjunto de arquivo deve ser preservado, primordialmente, no local de compilação de seus atos, no qual crescerá organicamente. 
Pode-se depreender das leituras das obras que, independentemente da consideração dos autores a respeito das origens do princípio, a base conceitual do Princípio da Proveniência consiste em não se misturar documentos de origens distintas, mantendo unidos os de mesma origem (ou proveniência). Assim, a organização dos documentos arquivísticos deve preservar a sua relação com a entidade produtora, de forma a se manter a organicidade, isto é, as relações dos documentos com o contexto funcional da sua produção.

\subsection{Duplo grau do Princípio da Proveniência}

Assim como alguns autores consideram o Princípio da Proveniência e o da Ordem Original como diferentes e complementares, outros apresentam o Princípio da Proveniência desdobrado em dois graus (CASANOVA, 1928; VÁZQUEZ, 1995; TAMBLÉ, 1993; ROUSSEAU; COUTURE, 1998; MARTíN-POZUELO CAMPILLOS, 1999; RUIZ RODRÍGUEZ, 1995; BELLOTTO, 2006).

Nessa perspectiva, Rousseau e Couture (1998, p.83) afirmam que:

No seu primeiro grau, o princípio da proveniência leva-nos a considerar o fundo de arquivo como uma entidade distinta. [...] E este primeiro grau tem a sua aplicação tanto no plano do valor primário dos documentos de arquivo como no plano de seu valor secundário. [...] No segundo grau, o princípio da proveniência exige que todos os documentos de um fundo de arquivo ocupem um determinado lugar que tem de ser respeitado ou restabelecido, caso a ordem primitiva ou a ordem original tenha sido modificada por qualquer razão.

Martín-Pozuelo Campillos (1995, p. 149-150) também defende o duplo grau da proveniência, lembrando que a mantenção da ordem original é uma extensão do respeito à "procedência" e que os dois "postulados" são fundamentais para o Princípio da Proveniência arquivística. Nesse caso, a autora considera duas premissas: a de se respeitar a proveniência e a de se preservar a ordem original dos documentos para se alcançar algo maior, que seria a proveniência arquivística. Essa autora reconhece um princípio definido a partir do Princípio da Proveniência, por ela denominado "Princípio de la Estructura Arquivística". A aplicação desse princípio remete a organização dos documentos à estrutura administrativa interna do organismo criador dos mesmos.

Bellotto (2006) também segue esse pensamento. Após a definição de proveniência, ela relata que esse princípio se desdobra em dois e afirma que alguns teóricos chegam a mesclálos. Já outros, afirma essa autora, diferem concretamente as origens alemãs do princípio, ou seja, o Provenienzprinzip e o Registraturprinzip. 
Lodolini (1993) e Heredia Herrera (1991) defendem a identidade conceitual de Proveniência e de Ordem Original, embora considerem que, em alguns casos, os dois termos são utilizados sem distinção dos seus objetivos ou conceitos.

Lodolini (1993, p. 153, tradução nossa) apresenta uma concepção ampla do Princípio de Respeito aos Fundos, afirmando que esse não significa somente o "respeito aos fundos, mas também, no interior de cada fundo". O autor acrescenta, ainda, que "somente a reconstituição incondicional da ordem original satisfaz a toda exigência científica" (LODOLINI, 1993, p. 198, tradução nossa). Ou seja, apesar de considerar importante o Princípio de Respeito aos Fundos, ele considera que a manutenção da ordem que criou o documento é essencial na análise e organização documental, de forma criteriosa.

Heredia Herrera (1991, p. 253) reconhece esse ideal, ao defender a imprescindibilidade do respeito à ordem original na organização de qualquer arquivo, fundo ou algo equivalente.

A partir desses autores, é possível depreender a relevância do Princípio de Respeito à Ordem Original, também conhecido como "metodo stórico" (LODOLINI, 1993), ordem natural (RUIZ RODRÍGUEZ, 2008), Registraturprinzip (SCHELLENBERG, 2006) e Princípio da Santidade9 (BELLOTTO, 2010), em complemento ao Princípio da Proveniência.

\subsection{Reapropriação e variações terminológicas}

Verificamos variações terminológicas do Princípio da Proveniência associadas a diferenças conceituais relacionadas, em alguns casos, a variações linguísticas e, em outros, a reapropriações ou adaptações do Princípio da Proveniência em determinados países.

O Provenienzprinzip, definido na Prússia, para alguns autores pode ser considerado como sinônimo do que foi determinado como Respect des fonds, na França (ROUSSEAU; COUTURE, 1998; LODOLINI,1993; BELLOTTO, 2010). Lodolini (1993, p.188) assim destaca, quando relata sobre uma mesma expressão em diferentes línguas, dadas como sinônimos: em francês, Respect des Fonds e Principe de Provenance; em inglês, Principle of Provenance e Principle of Respect des Fonds; em alemão, Provenienzprinzip; em espanhol, Princípio de Procedencia; em italiano, Principio di Provenienza e, em holandês, Herkomstbeginsel.

\footnotetext{
${ }^{9}$ O Princípio da Santidade é citado por Bellotto (2010) como uma questão polêmica na Arquivologia, devido ao entendimento restrito do termo. Segundo essa autora, a "santidade" não seria propriamente a ordem física dos documentos em sua fase corrente, mas o respeito à organicidade.
} 
Os arquivistas canadenses, Rousseau e Couture (1998), relatam que o Princípio da Proveniência foi adaptado pelos ingleses como archives group; pelos italianos e espanhóis, como fondo; e, mais tarde, pelos americanos e pelos canadenses como records group. Essa "adaptação", à qual os autores se referem, apresenta certo grau de identidade conceitual com o Princípio da Proveniência, já que é citado no mesmo parágrafo que explica a concepção e a evolução desse princípio.

Eastwood (1992) e Cruz Mundet (2008) estabelecem, em suas obras, a distinção entre o conceito europeu de fundo e o norte-americano de record group. Eastwood explica que, enquanto o record group, criado por Hilary Jenkinson, foi visto por muitos como comparável ou análogo ao conceito de fundo, existem diferenças importantes entre os dois. $\mathrm{O}$ autor destaca a aplicação para os norte-americanos que, na prática, dividem os registros de grandes agências em tamanhos convenientes para a administração. Esse desejo de evitar grupos muito grandes dentro da instituição arquivística levou ao estabelecimento de grupos de registros, faltando assim, as qualidades de completude e independência que foram enfatizadas por Jenkinson, assim como o próprio conceito de Proveniência.

Para Cruz Mundet (2008), o conceito de fundo está intimamente relacionado à documentação histórica em função da qual ele foi produzido. Dessa forma, é possível identificar com mais facilidade os organismos do passado e as suas estruturas hierárquicas. Já o conceito de record group está relacionado à preponderância da documentação contemporânea das administrações modernas, fluidas e poli-hierárquicas, o que dificulta a sua delimitação, segundo esse autor.

Heredia Herrera (1991, p.259), por sua vez, estabelece uma aproximação teórica dos conceitos de "método storico" ou "método archivístico" para os italianos, "provenienzprinzip" para os alemães, "respect des fonds" para os franceses, "respeto al origen" e "orden natural" para os espanhóis. Nessa comparação de termos, a autora demonstra a concordância com estudiosos que consideram o duplo grau do princípio da proveniência.

Alguns autores como Heredia Herrera (1991), Bellotto(2006) e Rousseau e Couture (1998) apresentam suas definições de fundo e de Princípio da Proveniência aproximando-as, mesmo que indiretamente. Bellotto (2006), por exemplo, expõe que "o fundo de arquivo tem origem teórica na formulação do Princípio da Proveniência" (BELLOTTO, 2006, p. 163) e cita autores canadenses para embasar a ideia de que, sem a aplicação do Princípio da Proveniência, não se pode falar em fundo de arquivo. É possível ratificar a afirmação acima da aproximação teórica a partir da definição de "fundo" pela autora, pois ela acrescenta que não se deve mesclar conjuntos de documentos gerados por instituições diferentes, independentemente da razão. 
Rousseau e Couture (1998, p. 92) afirmam que o conceito de fundo de arquivo tem sua origem na aplicação do princípio da proveniência e que também é "uma pedra de toque da prática arquivística".

Martín-Pozuelo Campillos (1996) aborda três conceitos, os quais, segundo ela, são derivados do primeiro nível de aplicação do Princípio da Proveniência: fundo de arquivo, procedência arquivística e quadro de classificação. Percebe-se, nesse momento, a diferenciação que a autora faz de termos muitos próximos: Princípio de Procedência e Procedência arquivística.

Após uma análise sobre o problema da contextualização histórica do Princípio da Proveniência, Martín-Pozuelo Campillos (1999, p.57) faz uma importante observação. Segundo ela, a uniformização acerca do Princípio da Proveniência está relacionada não só à terminologia, mas, também, à sua conceituação e contextualização, que se resume ao problema da falta de definição da natureza específica do conceito abordado. A solução para tal problema seria a análise dos conceitos que possibilitam o enunciado teórico do Princípio da Proveniência e, posteriormente, daqueles que se relacionam à sua prática.

\section{IMPORTÂNCIA E REPERCUSSÃO}

A importância do Princípio da Proveniência pôde ser verificada para a Arquivologia, de modo geral, na aplicação do princípio para a classificação e descrição dos documentos, bem como nas atribuições de outros princípios, como do Princípio da Territorialidade (CASANOVA, 1928; JENKINSON, 1965; ROUSSEAU; COUTURE, 1998), do Princípio da Ordem original (CASANOVA, 1928; ROUSSEAU; COUTURE, 1998; BRENNEKE, 1968; BERNER, 1983), como já citado anteriormente, e, também, do Princípio da Universalidade (ROUSSEAU; COUTURE, 1998; BERNER, 1983). Foi possível verificar, também, a aplicação do princípio relacionado à Teoria da Três Idades (ROUSSEAU; COUTURE, 1998).

Numa perspectiva geral, os autores normalmente fazem referência à importância do Princípio da Proveniência para a Arquivologia como disciplina, reconhecendo as suas contribuições para tal (RUIZ RODRÍGUEZ, 1995; ROUSSEAU; COULTURE, 1998; HEREDIA HERRERA,1991; CRUZ MUNDET, 2008; SCHELLENBERG, 2006). A maioria desses autores faz alusão ao que pode ser considerado como o grande marco para a área, que foi a Circular francesa de 1841, associando-o à construção da Arquivologia como disciplina. Além disso, relacionam essa evolução a uma das grandes contribuições desse documento que culminou na concepção arquivística contemporânea predominante de não mais se classificar documentos por assunto, considerando o fundo ao qual o documento pertence. 
Nesse sentido, Schellenberg defende que:

O princípio da proveniência suplantou o processo de dispor os papéis em conformidade com os assuntos. Destarte, um método de arranjo de todo dificultoso viu-se substituído por outro de caráter prático, pois os sistemas arbitrários de ordenação não são aplicados aos documentos sem que se complique infinitamente a tarefa do arquivista. (SCHELLENBERG, 1963, p.110).

O autor considera o Princípio da Proveniência tanto numa visão maximalista (diante da sua importância para a teoria arquivística), como numa visão mais aplicada, voltada para a classificação de documentos de arquivo, que deve respeitar a proveniência dos documentos. Ele afirma, ainda, que "o princípio serve para tornar conhecidas a natureza e significação dos documentos" (IDEM), além de manter a sua integridade. Desse modo, Schellenberg relaciona a importância da aplicação do Princípio da Proveniência com a razão de ser do documento.

Cruz Mundet (2008), nas suas justificações teóricas para a consideração da circular de 1841 como o marco oficial da origem do Princípio da Proveniência, afirma que o Princípio da Procedência tem representado o fundamento sobre o qual tem se concretizado o desenvolvimento da teoria arquivística, com destaque para a classificação. Para ele, a "classificação" consiste em agrupar os documentos de um fundo, de forma hierárquica, desde os mais gerais até os mais específicos, respeitando o Princípio da Proveniência e o da Ordem original.

Brenneke (1968) considera que, quando as fontes estão muito dispersas, o "Princípio da Origem" oferece ao pesquisador a única maneira possível para rastrear o documento. Esse autor ainda admite três funções para o Princípio da Proveniência: 1) como o Princípio de Ordem; 2) o princípio organizador para os arquivos; 3) e o princípio da pesquisa histórica.

Rousseau e Couture (1998) afirmam que a aplicação do Princípio da Proveniência elimina possíveis dispersões dos documentos em qualquer fase em que se encontrem, com o auxílio de instrumentos de pesquisa adequados. Esses autores afirmam, também, que a aplicação do princípio é o único meio de garantir tanto a integridade administrativa dos arquivos quanto o pleno valor de testemunho de um fundo, favorecendo, assim, a recuperação da informação. Esses autores chegam ao pico de caracterização dessa importância quando afirmam que esse princípio é a "lei que rege todas as intervenções arquivísticas" (ROUSSEAU; COUTURE, 1998, p. 79).

Heredia Herrera (1991) e Berner (1983) apresentam importantes considerações acerca da aplicação do princípio em questão na descrição. Para Heredia Herrera, a sua aplicação não deve aparecer somente na sistematização da classificação, mas, também, na descrição. Já 
Berner de forma inversa, apresenta a importância da descrição na Proveniência, ao afirmar que o controle que a descrição representa contribui para o aproveitamento do método da proveniência.

Em relação aos demais princípios, foi possível observá-lo na aplicação do Princípio da Territorialidade, como defendido por Casanova (1928) e por Rousseau e Couture (1994). Esses últimos autores atribuem grande importância do Princípio da Proveniência na origem do Princípio da Territorialidade, ao lembrarem que os documentos devem ser conservados nos serviços de arquivo do território nos quais foram produzidos. Essa afirmação demonstra, desse modo, a relação do Princípio da Territorialidade com o Princípio da Proveniência, já que a essência deste consiste no respeito do vínculo dos documentos com o seu produtor, isto é, num mesmo fundo.

Ainda segundo esses autores, é possível verificar uma consequência imediata ao se associar o Princípio da Territorialidade com o Princípio da Pertinência. Caso este tenha sido aplicado e os documentos tenham sido, então, classificados, segundo seu assunto, seria possível encontrar documentos de um mesmo fundo em países diferentes. Ou seja, os estudiosos canadenses novamente reconhecem a preponderância do princípio que tem sua raiz conceitual no Princípio da Proveniência (Princípio da Territorialidade), em detrimento daquele que diverge do padrão arquivístico adequado (Princípio da Pertinência).

Casanova (1928) dedica um capítulo da obra para Provenienza e Territorialitá, no qual relata que, com o conceito de Proveniência (que para ele está longe de ser uma simples integridade da série original) retoma-se o Princípio da Territorialidade o qual significa que os atos devem seguir o destino dos territórios em que foram escritos.

Além da aplicação do Princípio da Proveniência no Princípio da Territorialidade, os canadenses também observaram a sua importância na aplicação do Princípio da Universalidade. Para eles, "O princípio da proveniência permite aplicar o princípio da universalidade. Isto confere um método de trabalho ao arquivista, em virtude do qual ele considera primeiro as unidades de trabalho maiores e em seguida as mais pequenas" (ROUSSEAU; COUTURE, 1994, p. 85)."

Cruz Mundet (2008) também se refere à aplicação do Princípio da Proveniência tanto na Universalidade quanto na descrição, quando relata que, de acordo com o Princípio da Procedência, a descrição se aplica do geral para o particular. 


\section{CONSIDERAÇÕES FINAIS}

A partir da análise das 35 obras, voltada para o estudo do princípio fundamental da Arquivologia, foi possível chegar a conclusões importantes para o entendimento da evolução do princípio sob a ótica de renomados estudiosos da área, internacionais e nacionais. Sobre esse aspecto, não foi possível verificar algo que os autores brasileiros pudessem ter acrescentado para a análise do Princípio da Proveniência, embora tenham realizado importantes análises dos autores internacionais. Os autores internacionais que não foram mencionados, não fizeram considerações relevantes acerca do princípio.

De modo geral, foi possível verificar que, mesmo que existam aproximações, a Arquivologia ainda não possui consensos em nenhuma das quatro abordagens analisadas (histórica, conceitual, importância e repercussão do Princípio da Proveniência). Mesmo na abordagem histórica, a respeito da data de maior consideração da sua origem, que foi a circular francesa de 1841, não existe concordância entre os autores estudados. Schellenberg (2006), por exemplo, considera que o documento teve sua origem em 1839, por Guizot e, posteriormente, teria sido publicado por Natalis de Wailly, em 24 de abril de 1841. O autor acrescenta que as origens do Princípio do Respect des Fonds encontram-se tanto nessa circular quanto na exposição de Wailly, em 8 de junho do mesmo ano.

Entretanto, a maioria dos autores não faz uma análise histórica do princípio, como Schellenberg; considera, apenas, a sua origem na circular francesa, atribuindo o feito a Natalis de Wailly.

Ainda quanto à abordagem histórica, identificamos autores que relacionam as origens do princípio com outras datas, como Lodolini (1993) que considerou ordens pronunciadas pelo rei da França, em 1328, para manter a proveniência na classificação documental. Por outro lado, Cruz Mundet (2001) não considera outras origens, senão a de 1841. Para ele, as ordens referidas por Lodolini não perduraram no tempo, já que, no século XVIII, a classificação que predominava na França baseava-se em métodos temáticos e, após a Revolução Francesa, foi necessária uma nova forma de classificação, devido à situação problemática na qual se encontravam os arquivos classificados por assuntos.

Ademais, principalmente na obra de Lodolini (1993), outras datas foram verificadas e foi possível inferir que várias dessas "origens" estão associadas a ordens do Estado, voltadas para a preservação do contexto de produção e acumulação dos documentos, facilitando a sua recuperação. 
A respeito da conceituação, foi possível verificar algumas particularidades dadas pelos autores. Alguns caracterizam o Princípio da Proveniência como diferente do Princípio da Ordem original. Outros se referem a uma mesma definição para ambos. Há, ainda, aqueles que definem a proveniência em dois graus, sendo o Princípio da Ordem Original a segunda etapa para a aplicação do Princípio da Proveniência. Essas diversas definições abrem um leque de concepções acerca do princípio fundamental da Arquivologia, que transitam entre as três abordagens apresentadas.

As variações terminológicas nos demandaram bastante atenção, pois, em vários momentos, as variações de um país para outro estavam permeadas de conceitos que, por sua vez, caracterizavam importantes diferenciações dos termos. Por exemplo: o Princípio da Santidade foi interpretado por Bellotto (2010) de forma desmitificada, ao associar o termo à Organicidade e, portanto, ao fluxo natural da produção e acumulação documental e não à ordem estrita da produção corrente como fora visto.

A importância da aplicação do Princípio da Proveniência para a Arquivologia e para os demais princípios foi uma análise prazerosa. Para alguns daqueles autores que consideram a origem do princípio na circular francesa de 1841, esse documento fez com que a Arquivologia ganhasse o status de disciplina. Embora não tenha sido a maioria a fazer essa análise, renomados autores a fizeram, como Rousseau e Couture (1998), Heredia Herrera(1991) e Cruz Mundet (2008). Ao realizarem essa afirmação, os autores a justificaram com argumentos bem construídos. Rousseau e Couture (1998), por exemplo, afirmaram que, a partir do momento da publicação da circular, a Arquivologia saiu de uma anarquia.

De modo geral, o Princípio da Proveniência é uma coluna sustentadora dessa disciplina. Ele é, de fato, um princípio, compatível com os demais e adequadamente aplicável em todas as atividades arquivísticas. É possível perceber que, em parte, outros princípios coincidem com este, como a já citada confusão do Princípio com o de Respeito à Ordem Original. Para o Princípio da Territorialidade, a sua essência volta-se para a mantenção dos documentos no país de origem (fundo), sem mesclá-los com os documentos de outros países. O que seria essa orientação teórica senão a do conceito de Princípio da Proveniência?

É importante ratificar, portanto, a importância da aplicação do Princípio da Proveniência desde a produção do documento, para assim se garantir as relações orgânicas que existem entre o produtor e o documento.

Por fim, com todas essas considerações, foi possível perceber o quanto a Arquivologia ainda carece de consensos teóricos, oriundos de reflexões mais densas e não de meras aplicações empíricas. 


\section{Referências}

\subsection{OBRAS DA LITERATURA INTERNACIONAL}

ASSOCIATION DES ARCHIVISTES FRANÇAIS. Manuel d'Archivistique: théorie et pratique des Archives publiques en France. Paris: Direction des Archives de France, 1991.

BAUTIER, Robert-Henri. Les Archives. Paris: Gallimard, 1961.

BERNER, Richard C. Archival theory and practice in the United States: a historical analysis. Seattle: University of Washington Press, 1983.

BRENNEKE, Adolf. Archivistica: contributo alla teoria ed alla storia archivistica europea. Milano : Per i tipi dell'editore, 1968.

CARUCCI, Paola. Le fonti archivistiche: ordinamento e conservazione. 21a reimpressão. Roma: Carocci editore S.p.A, 2010.

CASANOVA, Eugenio. Archivística. Siena: Stab. Arti Grafiche Lazzeri, 1928.

COOK, Michael. The Management of information from Archives. England: Gower Publishing Company, 1986.

CORTÉS ALONSO, Vicenta. Documentacion y documentos. Madrid: Ministerio de Cultura/Dirección General de Bellas Artes, Archivos y Bibliotecas, 1980.

CRUZ MUNDET, José Ramón. Manual de Archivística. 7. ed. Madrid: Fundación Sãnchez Ruipérez, Pirámide, 2008.

DISTUTACION PROVINCIAL DE SEVILLA. Archivística: estúdios básicos. Sevilla, 1981.

DURANTI, Luciana. Diplomática: usos nuevos para una antigua ciencia. Carmona (Sevilla): S \& C ediciones, 1996.

EASTWOOD, Terry. The Archival Fonds: from Theory to Practice. Ottawa: Bureau of Canadian Archivists, 1992.

FAVIER, Jean. Les archives. 7 ed. Paris: Presses Universitaires de France, 1958.

GALLEGO DOMÍNGUEZ, Olga; LÓPEZ GÓMEZ, Pedro (1989). Artxibistikan sarrera = Introducción a la Archivística. Vitoria-Gasteiz: Servicio Central de Publicaciones. Gobierno Vasco, 1989. 
HEREDIA HERRERA, Antonia. Archivística general: teoría y práctica. 5 ed. Sevilla: Gráficas del Sur, 1991.

JENKINSON, Hilary. A manual of archive administration. 2 ed. London: Percy Lund, Humphries and Co., 1965.

LODOLINI, Elio. Archivistica: principios y problemas. 2 ed. Madrid: Editorial La Muralla S.A, 1993.

MARTÍN-POZUELO CAMPILLOS, M. Paz. La construcción teórica en archivística: el principio de procedencia. Madrid: Universidad Carlos III,1996.

MULLER, S.; FEITH, J. A.; FRUIN, R. Manual de arranjo e descrição. 2 ed. Rio de Janeiro: Arquivo Nacional, 1973.

NATIONAL ARCHIVES AND RECORDS SERVICE. A modern archives reader: basic readings on archival theory and practice. Washington: General Services Administration, 1984.

PEDERSON, Ann. Keeping archives. Sydney: Australian Society of Archivists, 1987.

ROUSSEAU, Jean-Yves; COUTURE, Carol. Os fundamentos da disciplina arquivística. Lisboa: Publicações Dom Quixote, 1998.

RUIZ RODRÍGUEZ, Antônio Angel. Manual de archivística. Madrid: Sínteses, 1995.

SCHELLENBERG, T. R. Arquivos modernos: princípios e técnicas. 6 ed. Rio de Janeiro: Fundação GetúlioVargas, 2006.

Documentos públicos e privados: arranjo e descrição. 2 ed. Rio de Janeiro: Fundação GetúlioVargas, 1980.

SOCIETY OF AMERICAN ARCHIVISTS; ASSOCIATION OF CANADIAN ARCHIVISTS. Canadian archival studies and rediscovery of provenance. Metuchen; London: The Scarecrow Press, 1993.

TAMBLÉ, Donato. La teoria archivistica italiana contemporanea: profilo storico critico (19501990). Roma: La Nuova Italia Scientifica, 1993.

TANODI, Aurelio. Manual de archivología hispanoamericana: teorías y principios. Córdoba: Universidad Nacional, 1961.

VÁZQUEZ, Manuel. Manual de Selección Documental. 3 ed. Córdoba: S\&C ediciones, 1995.

\section{2 OBRAS DA LITERATURA NACIONAL}


BELLOTTO, Heloísa Liberalli. Arquivos Permanentes: tratamento documental. 4 ed. Rio de Janeiro: Fundação GetúlioVargas, 2010.

JARDIM, José Maria. Sistemas e políticas públicas de arquivos no Brasil. Niterói: Eduff, 1995.

- Transparência e opacidade do Estado no Brasil: usos e desusos da informação governamental. Niterói: Eduff, 1998.

LOPES, Luís Carlos. A informação e os arquivos: teorias e práticas. Niterói: EDUFF, 1996.

- A gestão da informação: as organizações, os arquivos e a informática aplicada. Rio de Janeiro: Arquivo Público do Estado do Rio de Janeiro, 1997.

PAES, Marilena Leite. Arquivo: teoria e prática. 3 ed. Rio de Janeiro: Fundação GetúlioVargas, 1991.

6.3 Referências complementares

ARQUIVO NACIONAL. Dicionário Brasileiro de Terminologia Arquivística. Rio de Janeiro: Arquivo Nacional, 2005.

MARQUES, Angelica Alves da Cunha. Interlocuções entre a Arquivologia nacional e a internacional no delineamento da disciplina no Brasil. 2011. Tese (Doutorado em Ciência da Informação), Universidade de Brasília, Brasília.

Submetido em: 12/2012

Aceito para publicação em: 02/2013 